\title{
Analysis and Countermeasures of PPP Project Implementation
}

\section{Difficulties}

\author{
Yifeng $\mathrm{Xu}^{1}$ and Wei Chang ${ }^{2}$ \\ ${ }^{1}$ School of management and engineering, Zhengzhou University, China \\ ${ }^{2}$ China Machinery TDI International Engineering Co.,Ltd, China
}

\begin{abstract}
Since the beginning of 1995, the model of PPP project construction was introduced in China. It has been widely used in many fields such as energy, municipal, and so on. It has accumulated a lot of experience in improving the investment system structure and guiding the social capital into the infrastructure field. But the mode of PPP project construction in the implementing process in different environment often encounters a lot of problems. Based on a large amount of analysis on the existing literature, this paper resorts out the PPP project model combining the problems occurred in the implementation process of PPP project, and summarizes corresponding countermeasures aiming at the problems in order to provide help for PPP project implementation in the future.
\end{abstract}

Keywords. Public Private Partnership, Problem, Strategy.

\section{Introduction}

PPP originates in western countries. In 80 s of last century, in the overall privatization ideas, the British government began to advocate PPP mode. The British government is a pioneer advocate of PPP, and it is also the promoters of PPP [1]. PPP is the abbreviation of three English words which include private, partnership, and public. PPP itself is a concept whose meaning is covering a wide range. Because of the different ideologies, all countries have different interpretations of PPP. The international mainstream translation is capital cooperation between the government and society $[2,3]$.

The essence of PPP is that the government provides public services to the public. On the surface, PPP's origins began with the government's lack of funds in public spending. Many governments choose to develop PPP when they are under great pressure to provide infrastructure. It is conducive to reduce the short-term public expenditure pressures, and to enhance the efficiency and quality of public services to a certain extent. In the final analysis, the definition of PPP is actually a sentence which refers that the government makes full use of the money, technology, talents and management experience of the social capital in order to improve the quality and efficiency of public service supply through sign a contract.

The main role of the government in the PPP model will be providers of public services rather than direct producers. But there is a lack of perfect legal system in the PPP construction mode, although the relevant laws can be referred to, but cannot fully cover a variety of problems which may be occurred in the PPP construction projects [4]. In addition, because of some government officials lacking the necessary professional knowledge, skills and scientific assessment methods, or the using of the old management method management, it is easy to appear mistakes in decision-making. At the same time, ineffective government regulation will affect the implementation of the PPP construction model. Based 
on this, this paper analyzes the current implementing situation and the problems occurring of the PPP construction mode, puts forward the corresponding countermeasures, and aims at improving the implementing effect of PPP construction mode [5].

The contents of this paper are as follows. The second section describes the characteristics of PPP construction mode. The third section analyzes the difficulties in the implementation process of the current PPP construction mode. The fourth section summarizes the corresponding countermeasures to solve the problem. Finally, the conclusion discusses the research content of this paper and puts forward the prospect.

\section{Main characteristics of PPP}

\subsection{Partnership}

Partnership is the first major character of PPP, and all the PPP projects which are successfully implemented are built on the partnership [6]. It can be said that the partnership is one of the most basic and critical relationship in PPP, and there will be no PPP if there is no partnership.

Compared to other relationships, a significant unique point in the partnership between the private sector and the government's public sector in PPP is consistent with the project objectives. The reason why the public sector and private sector cooperate and form partnerships is that they have the same goal. The goal is to achieve the most products or services with the least resources in a specific project. Private sector is to achieve the pursuit of their interests according to this goal, while the public sector is to achieve the pursuit of public welfare and interests according to this goal.

\subsection{Benefit sharing}

Benefit sharing is the second character of PPP. What needs to be clear here is that the public sector in PPP and private sector do not share the profits, but need to control the probable high profits in the private sector. That's to say that the private sector is not allowed to form an excess profit in the implementation process of the project. The main reason is that any PPP project is a public welfare project, and do not aim to maximize profits.

It is worth to note that benefit share here is not only means sharing the social outcomes of PPP, but also means making the private sector, private enterprises or institutions which are as the participants to obtain relatively peaceful, stable investment returns [7].

\subsection{Risk sharing}

The third feature of PPP is risk sharing. Partnership not only means benefit sharing, but also means risk sharing. In PPP, which is compatible with the market economy rules, the benefit and the risk are also corresponding. Risk sharing is another foundation of partnership besides the benefit sharing. If there is no risk sharing, it is impossible to form the partnership.

In PPP, the character of risk sharing between the public sector and the private sector is a significant sign to differ other forms of transaction between the public sector and the private sector [8].

If each of the risks can be assumed by partners who can deal with the risks well, there will be no doubt that the cost can be minimized throughout the infrastructure project.

\section{Analysis of difficulties in the implementation of PPP project in China}

\subsection{The partnership is not solid enough}

Partnership in China refers to that a natural person, legal person and other organizations establish in the territory of China in accordance with the Law of the People's Republic of China on Partnerships. It is a profit organization in which 
there are two or more than two partners make the partnership agreement, joint contribute and adventure, share the benefit and risk to operate the common cause.

The partnership in the PPP mode is more special. It is reflected in the following respect. One of the partners is the government or designated by the government. Under the background of public ownership as the foundation of economy in our country, the government has a deeper meaning. This leads the partnership's implementation of the legal principle, four principles, based on the mutual trust to be a problem. On the one hand, government's trust in social capital, especially private capital is not high. A lot of requirements are not high in the PPP project which may only cost two or three billions but the governments often require enterprises which have billions of dollars of its own funds to participate in the project. On the other hand, the universal acceptance of private capital for the government's sincerity, the corresponding policy continuity is low. The cycle of PPP project is generally longer, and the uncertainty is very high. All of these lead to that the partnerships are hard to build in the specific PPP project.

\subsection{It is hard to achieve the benefit sharing}

The public sector and the private sector in PPP projects are not to share profits. And the government also needs to control the high profits of the private sector. That is not allowing private sector form the excess profit in the process of the implementation of the project. In essence, it produces an incompatible contradiction with the capital of the profit driven. In our country, the development time of private capital is relatively short, foundation and strength is not strong, and it is in the growth and cultivation period. It requires high returns on profits in internal logic, which is the reflecting of scarcity of capital.

While in the PPP project, the government is often in a strong position. Pricing power and the price adjustment of public services is determined by the government in general. When the market has not yet formed, due to the aircraft effect which means the two sides jointly strive to cultivate the market makes the benefit sharing exist in a short period of time. However, once the market is formed, the inconsistency of the goal between the two sides often lead the balance of benefit sharing soon to break, leading to part company each going his own way. It can be more fully reflected in the case of the Quanzhou Ci tong bridge in which private capital hope that the government does not build other competitive projects in order to get the stable high income, while the government wants to build other competitive projects in order to achieve better social services, which leads to the difficulty of the operation of PPP project. Working together can be realized but sharing the good things cannot be realized, benefit sharing becomes a kind of ideal to some extent.

\subsection{Risk sharing evolving into undertaking risk by oneself}

In PPP, it is generally required that the public sector assume associated risks in which they have their own advantages as far as possible and let the other party to bear the risk as little as possible to minimize the cost of the entire project. But due to the specific to a single PPP project, the barriers between departments highlights. Implementation of land and the planning, matching water, electricity, roads and so on should be the responsibility of the government to assume and defuse the risk, but be assumed by private party as an inescapable duty. Risk sharing evolves into undertaking risk by oneself. For an example, after the completion of a PPP sewage treatment plant, it is failed to put into operation for many years just because the construction of the pipe network needed is not in place.

Especially after the increasing of the PPP project, even though the government's ability to share the risk and coordination capacity increase, its increase range is far behind the increase rate of PPP project. For a single PPP project, the sense and the ability of risk sharing of government is weakened. It pushes partners in PPP project to bear the corresponding risks in order to ensure their own interests have so that the cost of the project increases.

For the government, especially for the government department, it is the promotion of a number of PPP projects. The specific progress of a single PPP project does not affect the government offer the public service. The awareness to assume the risk forwardly in subjective is not strong. In extreme circumstances, the risk of the project may be increased unconsciously. And for private investors, a PPP project may determine whether they can survive. Their risk prediction 
and risk appetite determine that they have to take more risks. Sometimes, to get some projects, they have to agree with all the things.

\section{Corresponding countermeasures}

In the strict sense, the division of the analyzing difficulties in the third part is not very scientific. The main reasons are as the following. First, the distinction boundary between the difficulties is not obvious. Second, the perplexing relationship exists among each other, and it can't be simply separated. Using the classification and description method is only in order to analyze the problem relatively incisively. Therefore, in the discussion of the corresponding countermeasures, it is not suitable to use the method of point-to-point. It is necessary to consider the relationship between countermeasures and the various difficulties, solving mechanism, solving degree and so on. The following is a brief discussion on the corresponding countermeasures.

\subsection{Cultivate the spirit of contract combining with the characteristics of Chinese market economy}

From the perspective of the connotation of contract spirit, the agreement between it and the value system the structure of social ethics of Chinese society are in a high degree. They generally recognize the honest and trustworthy, encourage the hard-working rich, and abandon the gains without working. In civil activities, the freedom and equality are highly guaranteed. These are the favorable conditions for fostering the contract spirit in China. It should be noted that family oriented economies are shrinking with the substantial increase in social productivity. However, the change of traditional concept requires a lot of time. In the country which cries up the rule by man and pecking order for thousands years, implementing the concept of rule of law which uses the all men are born equal as the core with force is not easy to success.

It should be said that the China market economy is still largely rely on family oriented. Individual industrial and commercial households, small processing plants, and the small family business are still the mainstream of our country. In economic activities, in addition to obey the laws and regulations of the state, most of these small and micro enterprises also obey the constraints of Chinese social ethics and values. This can also be referred to as the contract spirit of Chinese style. With the accumulation and subliming of this spirit coupled with the further development of the economy, the complete idea of strictly abide by contracts and keep one's word will gradually internalize into our social ethics structure, which makes the value base of the implementation of PPP project to be stable.

\subsection{Understand the significance of PPP project correctly, eliminate the prejudice and make partner be the real partner}

The substance of the PPP project is the government to provide public services to the public. PPP originated from the government's lack of money, but it is definitely not to solve the problem of government having no money. The government makes full use of the money, technology, talents and management experience of the social capital in order to improve the quality and efficiency of public service supply with the way of making the contract. It not only solves the problem of money, but also solves the problem of the long-term mechanism. In fact, the real source power which influences the development of PPP is the power of public management reform. Increase and optimize the supply and management efficiency of public goods and services through changing the institutional mechanisms, reducing market access, breaking the monopoly and introducing competition.

This requires that the PPP project participants eliminate the bias between each other, especially the bias of government departments on private capital. They should carefully examine, select partners from the perspective of increasing and optimizing the supply and management efficiency of the government's public goods and services, rather than hold the wrong ideas and prejudices that PPP is borrowing money in a disguised form, digesting the crisis brought 
by local government debt to response to demand of the higher level of leadership, and finally make private capital in the PPP project be in a true partnership position.

\subsection{Encourage, foster private capital to further expand the scale}

After thirty years of reform and opening up, China's private capital has been developed by leaps and bounds from scratch and from small to large, and greatly improves and enriches the market economy. According to the relevant data of the National Bureau of statistics, the total amount of private capital has exceeded the state capital. However, the single body of private capital is very small, and it cannot be compared with the state-owned capital. For the PPP project, the initial funding requirements limit the involvement of private capital to a certain extent. Therefore, encourage and foster private capital to further expand the scale, so that it can adapt to the rigid requirements of the PPP project. At this stage, the government can try to make the pension fund, social security fund enter the PPP project conditional, replenish the short board of scale shortage of private capital.

\section{Conclusion}

Above all, PPP model has been applied in many fields in our country. As a new mode of operation, PPP reflects the more tenacious vitality. On the one hand, China's public service infrastructure is still not perfect, it needs a huge investment. But the government's financial resources are limited and need funds to enter. On the other hand, the total amount of private capital is gradually increasing, but the investment channel is narrow. The generalized M2 currency is high, and it is necessary to open up new areas of investment. Under the common effect of the two factors, the PPP project mode of our country will be further extended and used in the next period of time.

Based on the concept, connotation and essence of PPP project, this paper makes a brief analysis of the difficulties in the implementation of PPP project. In comparison with the implementation environment of the PPP project in other countries, think qualitatively that the lack of contract spirit affects the implementation of the PPP project, and the inherent prejudice of private capital affects the acceptance and absorption capacity of PPP project to private capital. Besides, the partnership which is loose and lack of trust will directly affect the operation of the PPP project, and may lead to the failure of the project.

Based on the policy perspective, on the macro, PPP project needs more developed market economy, and needs the good faith as the core of the general contract spirit. Besides, it needs the government who has the courage to break the barriers and bent over. What' $s$ more, it needs social public to be understanding and tolerant. On the micro level, it needs to change bias of the no business is not evil and believe and understand each other. It needs reasonable profit distribution and appropriate risk sharing. And it needs third party coordination platform which is objective and fair and can make the dialogue equal.

The operation cycle of PPP project is very long. There is no project which has experienced the whole process so far in our country. The experience of operation, maintenance and transfer and existing problems need to be further considered. In addition, another important role in the PPP project is that the user's behavioral characteristics and its impact on the PPP project have not yet been described and need further investigation and study.

\section{References}

1. Tang L Y, Shen Q, Cheng E W L. A review of studies on Public - Private Partnership projects in the construction industry. International Journal of Project Management, 2010, 28(7):683-694.

2. Forrer J, Kee J E, Newcomer K E, et al. Public - Private Partnership and the Public Accountability Question. Public Administration Review, 2010, 70(3):475 - 484.

3. Hwang B G, Zhao X, Gay M J S. Public private partnership projects in Singapore: Factors, critical risks and preferred risk allocation from the perspective of contractors. International Journal of Project Management, 2013, 31(3):424-433.

4. Chan A P C, Yeung J F Y, Yu C C P, et al. Empirical Study of Risk Assessment and Allocation of Public-Private 
Partnership Projects in China. Journal of Management in Engineering, 2011, 27(3):136-148.

5. Yongjian Ke, ShouQing Wang, Albert P. C. Chan. Risk Misallocation in Public-Private Partnership Projects in China. International Public Management Journal, 2013, 16(3):438-460.

6. Cheung E, Chan A P C. Revitalizing Historic Buildings through a Partnership Scheme: Innovative Form of Social Public - Private Partnership. Journal of Urban Planning \& Development, 2014, 140(1):94-95.

7. Lee C H, Yu Y H. Service delivery comparisons on household connections in Taiwan's sewer public private-partnership (PPP) projects. International Journal of Project Management, 2011, 29(8):1033-1043.

8. Bank W. Building Integrated Markets within the East African Community: EAC Opportunities in Public-Private Partnership Approaches to the Region's Infrastructure Needs. World Bank Publications, 2014. 